\title{
0 que é a psicologia concreta: contribuições de Lev. S. Vigotski
}

Lígia Márcia Martins

\section{RESUMO}

Este artigo tem como objetivo corroborar a resposta a psicologia concreta, tendo como referências as proposições de Vigotski. Para tanto apresenta, introdutoriamente, elementos da crítica tecida por este autor à psicologia tradicional presentes no ensaio "O significado histórico da crise da psicologia. Uma investigação metodológica", bem como sua defesa em prol de uma psicologia científica, concreta. Na sequência, recorrendo ao estofo filosófico materialista histórico-dialético da psicologia vigotskiana, apresenta uma sistematização acerca dos traços característicos fundamentais de uma psicologia concreta, quais sejam: o enfoque materialista; a constatação de que na base de todas as relações sociais estão as relações sociais de produção; o apelo à luta contra as condições objetivas e subjetivas que alienam o trabalho e o trabalhador e, por último, a adoção do método materialista dialético. À guisa de finalização, esses traços são ilustrados no tratamento dispensado por Vigotski à necessidade de formulação de uma psicologia geral; no enfoque ontológico e gnosiológico dispensado ao desenvolvimento do psiquismo humano bem como por meio do conceito de vivência, considerada pelo autor como unidade indissolúvel entre pessoa e situação social de desenvolvimento.

Palavras-chave: Psicologia Concreta; Vigotski; Materialismo Histórico-Dialético.

\section{ABSTRACT}

\section{What is concrete psychology? Contributions by Lev S. Vigotski}

This paper aims to corroborate the answer to what is concrete psychology, having as reference Vygotsky's propositions. To this end, presents introductory elements of the critique made by this author to the traditional psychology in the essay "The historical meaning of the crisis in psychology. A methodological investigation", as well as its defense of a concrete, scientific psychology. Then, using the historical and dialectical materialism of Vigotski's psychology, this paper presents a systematization of the concrete psychology's fundamental characteristics, namely: the materialist approach; the realization that the basis of all social relations are the relations of production; the call to fight against the objective and subjective conditions that alienate work and workers and, finally, the adoption of the dialectical materialist method. In conclusion, these elements are illustrated in how Vigotski discusses the need to formulate a unique psychology; in the ontological and gnosiological focus given to the development of the human psyche as well as through the concept of "life experience", considered by the author as an indissoluble unit between person and social situation of development.

Keywords: Concrete Psychology; Vygotsky; Dialectial and Historical Materialism.

\section{INTRODUÇÃO}

Este artigo visa corroborar a resposta para a seguinte interrogação: 0 que é a Psicologia Concreta? Para tanto, recorremos às contribuições de Vigotski haja vista a sua proeminente contribuição para a superação dos enfoques idealistas e mecanicistas imperantes na psicologia desde as suas origens. O referido autor empreendeu uma acurada crítica à psicologia como ciência originária e amoldada ao contexto do Século XIX - naquilo em que ele marca a

\section{Sobre os autores}

L. M. M.

https://orcid.org/0000-00024293-9580

Universidade Estadual Paulista Júlio de Mesquita Filho - São

Paulo, SP

ligia.martins@unesp.br

\section{Direitos Autorais}

Este é um artigo de acesso aberto e pode ser reproduzido livremente, distribuído, transmitido ou modificado, por qualquer pessoa desde que usado sem fins comerciais. 0 trabalho é disponibilizado sob a licença Creative Commons CC-BY-NC.

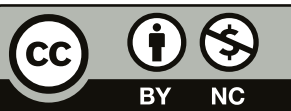




\section{M." INTERACÃO EM 2. PSICOLOGIA}

hegemonia da organização social burguesa e do cientificismo positivista; bem como uma análise radical de seus fundamentos e dos possíveis rumos deles decorrentes.

O bielo-russo Vigotsky (1997), trabalhando sob o cenário pós-revolucionário da então União das Repúblicas Socialistas Soviéticas, escreveu em 1927 o clássico estudo "O Significado Histórico da Crise da Psicologia: Uma Investigação Metodológica". Nele, colocou sob análise um traço característico à psicologia desde seu surgimento, qual seja, contemplar uma vasta gama de objetos, métodos e teorias, dado que a converte numa ciência multifacetada. Essa abrangência, por um lado, evidencia a adoção da lógica formal, binária, no âmbito epistemológico do Século XIX e início do Século XX, e por outro, a prevalência das concepções abstratas acerca do desenvolvimento psíquico. Aliando estas duas orientações, a psicologia tradicional edificou-se sob a marca de dualismos rígidos, a exemplo de objetividade-subjetividade, corpo-mente, individual-social, consciente-inconsciente, normal-patológico, dentre outros.

Para Vigotsky (1997), era premente a análise e coordenação crítica dos rumos da psicologia, tendo em vista o alcance de princípios gerais e, consequentemente, a construção de uma coerência teórico-metodológica nessa ciência. Depreendemos que este foi um dos maiores desafios assumidos por este autor, ao apontar as lacunas da psicologia e desnudar suas inúmeras incompletudes e, igualmente, advogar a necessidade de formulação de uma psicologia geral. Segundo ele, as várias disciplinas, ou vertentes, instituintes da psicologia se firmaram independentemente e calcadas num paradoxo: ao se edificarem, cada uma delas, na base de preceitos gerais próprios, afırmaram a inexistência de uma psicologia geral, mas ao mesmo tempo, evidenciaram a impossibilidade da investigação científica em detrimento dela.

Portanto, Vigotski considerou que as lacunas ou incompletudes da psicologia não seriam resolvidas pela proposição de novas ou outras abordagens, afirmando que seus esforços não iriam nessa direção, mas sim, em busca das bases gerais sobre as quais a psicologia científica pudesse ser edificada. Tal fato, porém, não significa que ele estivesse secundarizando os diversos objetos assumidos pelas várias vertentes psicológicas. Ele era anuente com o fato de que essa ciência deveria debruçar-se sobre uma vasta gama de fenômenos, tais como o psiquismo humano e suas propriedades, o comportamento, o inconsciente, etc. 0 problema afeto à crise da psicologia não seria, pois, da ordem dos fenômenos aos quais ela se dedica, mas sim, das formas pelas quais o faz, ou seja, da ordem do método.

Nas palavras do autor:

A possibilidade da psicologia como ciência é, antes de tudo, um problema metodológico. Em nenhuma ciência existem tantas dificuldades, controvérsias insolúveis, uniões de questões diversas, como em psicologia. 0 objeto da psicologia é o mais difícil que existe no mundo, o que menos se deixa estudar; sua maneira de conhecer há de estar repleta de subterfúgios e precauções especiais para proporcionar o que dela se espera (Vigotsky, 1997, p. 387).

Com essa proposição, entre outras, ele indicou dois caminhos possíveis à psicologia: ou como ciência, ou como um conjunto de visões fragmentárias e, nesse caso, impossível como ciência. Dessa forma, afırmou que a psicologia como ciência dos fenômenos psíquicos reais, isto é, concretos, precisava ultrapassar-se a si mesma, superando as abstrações e as atomizações lógico-formais sobre as quais se desenvolvera. Do ponto de vista lógico-metodológico, essa superação só seria possível na esteira de um método apto a captar os fenômenos psíquicos em sua totalidade, movimento e contradição, isto é, na esteira do materialismo dialético. Para Vigotsky (1997, p. 389), "a dialética abarca a natureza, o pensamento, a história; é a ciência mais geral, universal até o máximo. Essa teoria do materialismo psicológico ou dialética da psicologia é o que eu considero psicologia geral".

A nosso juízo, essa teoria do materialismo psicológico ou dialética da psicologia identifica-se com o que seja psicologia concreta.

\section{A PSICOLOGIA CONCRETA COMO 'TEORIA DO MATERIALISMO PSICOLÓGICO OU DIALÉTICA DA PSICOLOGIA"}

A tarefa que ora se apresenta visa expor, ainda que em linhas gerais, o estofo materialista histórico-dialético da psicologia concreta tendo em vista extrair dele as características centrais dessa psicologia, e que entendermos presentes por interioridade na psicologia vigotskiana. Entendemos que na ausência dessa clareza filosófica não apreenderemos a essência do que seja a teoria do materialismo psicológico.

Os esforços de Vigotski em direção à elaboração da psicologia científica encontram amparo numa concepção filosófica determinada, o materialismo histórico-dialético, ou seja, na epistemologia marxiana, legado nos deixado por Karl Marx e Friedrich Engels pelo qual revolucionam - do ponto de vista filosófico, a concepção de ser humano, de sociedade e das imbricadas relações que se travam historicamente entre ambos, entre outras questões. Concebemos que por materialismo histórico devemos apreender o núcleo teórico-filosófico das proposições desses dois autores, pelas quais, via decodificação materialista dialética dos fenômenos da realidade, elucidam as concepções acerca das relações entre ser humano e natureza, organização social, desenvolvimento dos indivíduos, cultura, etc.

Marx e Engels (1993) partem do fato de que todos os fenômenos que instituem a realidade têm origem material, o 


\section{H. INTERACÃO EM ET PSICOLOGIA}

que significa dizer, existem objetiva e independentemente da consciência que se tenha sobre eles. A matéria - que ultrapassa o âmbito da materialidade física, é, pois, o dado fundante da existência. Sendo assim, os conteúdos da consciência não emergem dela mesma, como creem os idealistas, mas resultam da captação do mundo objetivo pelos sentidos. Os conteúdos da consciência refratam os alcances da captação do real e as vias pelas quais os seres humanos o tornam cognoscível.

Portanto, consideramos que um primeiro traço característico da psicologia concreta seja seu enfoque materialista acerca da vida humana e, por conseguinte, dos fenômenos psicológicos. Tal fato demanda colocar em destaque as condições concretas que lhe conferem sustentação e, para além disso, levar em conta que tais condições não são equânimes na sociedade de classes, dado que ela carrega consigo condições de desenvolvimento humano injustas e desiguais para imensa parcela da população. 0 fundamento materialista da psicologia concreta exige que ela se alie às lutas sociais por uma outra ordem social, superadora dos obstáculos que se impõem à formação omnilateral de todos os indivíduos. Ela é, então, uma psicologia revolucionária.

Ademais, a realidade objetiva não é estática, mas um constante processo de transformações, o que a coloca como dado histórico. Tais transformações, por seu turno, há muito deixaram de ser naturais ou fortuitas, subjugando-se, pois, à relação entre ser humano e natureza. Ou seja, o homem, como parte da natureza só pode sobreviver por seu constante metabolismo com ela, metabolismo esse consubstanciado em sua atividade vital, isto é, no trabalho. Nessa acepção, a história é o produto dos modos pelos quais os seres humanos produzem sua existência ao longo do tempo, num processo cujo traço central é a sua dimensão teleológica. Sendo assim, o trabalho operou e continua operando decisivamente na formação humana.

Ocorre, porém, que essa produção não é um ato isolado, posto que os homens e mulheres não produzem individualmente suas condições de existência, pelo contrário, só o fazem em comum e interdependentemente. Nenhum indivíduo, por mais reduzidas que fossem suas necessidades, conseguiria produzir por si mesmo aquilo que o atendimento delas demanda, e é por isso que sob quaisquer condições a produção humana será sempre produção social. 0 trabalho, por sua natureza, é uma atividade coletiva, intencionalmente projetada, demanda meios e resulta em produções; e é exatamente por ele que os indivíduos constroem não apenas os meios para sua sobrevivência, mas sobretudo, a si mesmos. 0 traço essencial da história humana reside, pois, nos modos de produção sob os quais ela se erige, ou seja, na história do desenvolvimento das relações sociais de produção.
Em face do exposto entendemos, então, que o segundo traço característico da psicologia concreta seja a clareza de que na base de todas as relações sociais estão as relações sociais de produção, de sorte que o elemento central na caracterização de uma sociedade não reside nas ideias que se tenha sobre ela, mas na objetividade das relações de produção que nela se pratica. Nas palavras de Duarte (1993, p. 40): "Os homens fazem as circunstâncias, isto é, se objetivam, mas as fazem a partir de suas possibilidades objetivas e subjetivas resultantes do processo de apropriação das circunstâncias existentes, isto é, as circunstâncias fazem os homens" (grifos no original).

Cabe ainda destacar que no modo hodierno de relações de produção, no capitalismo, se instala uma ruptura entre os homens e mulheres e suas condições de existência. Nas formas de organização pré-capitalistas imperava uma unidade imediata entre ambos e o objetivo econômico era o de produção de valores de uso. Diferentemente, no sistema capitalista a produção de valores de uso cede espaço e importância para a produção de valores de troca. Marx (1986, p. 447) afirma que no capitalismo "a produção aparece como objetivo do homem e a riqueza como objetivo da produção", num processo que absolutiza o valor de troca e confere primazia absoluta à produção de mercadorias. A propriedade privada - primitivamente instituída nos regimes escravocratas e feudal, complexifica-se gigantescamente, fazendo coexistirem aqueles que detém a propriedade privada dos meios de produção e aqueles que, desprovidos dela, carecem vender o que possuem: a força de trabalho. Instala-se, assim, o fenômeno da alienação.

No " 1 Manuscrito econômico-filosófico", de 1844, Marx (2004) analisa o trabalho alienado destacando a alienação na relação entre o indivíduo e o produto de seu trabalho, quando então as objetivações do trabalhador deixam de ser objetos de suas apropriações; entre o indivíduo e o processo de produção - que se torna alheio a ele e com o qual não tem vínculo de pertencimento e entre o indivíduo e o gênero humano, num processo que culmina no enriquecimento do acervo cultural em igual medida do empobrecimento do indivíduo, impossibilitando a finalidade última da existência humana, que é a objetivação de cada pessoa como ser humano genérico.

Por conseguinte, o indivíduo alienado do produto do seu trabalho, do processo de produção e de sua vida genérica, aliena-se de si mesmo, fato que se estende à relação para com os outros indivíduos. Marx (2004) deixa claro que a alienação do trabalho e do trabalhador resulta de condições que são histórico-sociais, e não naturais, seu fundamento radica-se na propriedade privada dos meios de produção, de maneira que a luta contra a alienação se identifica com a luta pela abolição de seu fundamento.

O empobrecimento da individualidade humana em condições de alienação abarca tanto sua expressão no âmbito do 


\section{H. INTERACÃO EM PSICOLOGIA}

trabalho quanto no âmbito da vida pessoal, uma vez que a ordem de relações políticas e econômicas subordinam a si o próprio desenvolvimento do psiquismo. Ora, se esse desenvolvimento é o objeto de estudo da psicologia, uma psicologia que se queira científica não pode furtar-se à análise radical das bases sobre as quais ele ocorre, e por essa razão identificamos como terceiro traço característico de uma psicologia concreta a luta contra as condições objetivas e subjetivas que alienam o trabalho e o trabalhador.

O quarto e último traço que avaliamos característico da referida psicologia e que consideramos fundante do arcabouço teórico vigotskiano não poderia ser outro senão a adoção do método materialista dialético. Segundo Kopnin (1978, p. 65):

A dialética materialista reflete, deste modo, as leis do movimento dos objetos e processos do mundo objetivo, incluindo o homem e sua sociedade, que atuam como princípios e formas de atividade do pensamento. E nesse sentido, a dialética marxista desempenha, em nova base filosófica, as funções quer de ontologia, quer de gnosiologia, lógica e antropologia filosófica, sem reduzir-se a qualquer uma delas separadamente ou à soma de todas.

Na condição de método, o materialismo dialético sistematiza princípios que orientam a construção do conhecimento de todos os aspectos de um fenômeno e, sobretudo, das relações mútuas, das intervinculações e interdependências que existem entre eles, primando por ser um método de compreensão do real como totalidade. Destarte, a lógica dialética desponta como possibilidade para a superação de dicotomias e, especialmente, dos dualismos lógico-formais que ainda se revelam hegemônicos no campo científico.

Em conformidade com Kosik (1976), para o materialismo dialético a construção do conhecimento objetivo exige a superação da apreensão aparente do fenômeno em direção à sua apreensão essencial. Prescreve que o mundo empírico representa apenas a manifestação fenomênica da realidade em suas definibilidades exteriores, ou seja, que os fenômenos imediatamente perceptíveis se desenvolvem à superfície da essência do próprio fenômeno. Haja vista que o essencial não se revela de modo imediato na concretude aparente do fenômeno, sua captação resulta do desvelamento de suas mediações e contradições internas, via pela qual se abrem as possibilidades para sua apreensão concreta.

Em suma, a adoção do método marxiano pressupõe como ponto de partida a apreensão do real empírico, imediato, que convertido em objeto de análise por meio dos processos de abstração resulta numa apreensão de tipo superior, expressando-se como concreto pensado. Contudo, essa ainda não é a etapa final do processo, uma vez que as categorias interpretativas, as estruturas analíticas constitutivas do concreto pensado precisam ser contrapostas em face do objeto inicial, agora captado não mais em sua imediaticidade sensível, mas sim, como síntese de múltiplas determinações e relações diversas.

\section{À GUISA DE FINALIZAÇÃO}

Principiamos este artigo destacando o papel que Vigotski desempenhou em direção à superação dos limites da psicologia tradicional e para a elaboração de uma psicologia científica, concreta, tomando como base o ensaio "O Significado Histórico da Crise da Psicologia: Uma Investigação Metodológica". Da análise empreendida pelo autor, evidenciamos que a psicologia, desde as suas origens se fez marcada pela ausência de um paradigma e, pela ausência de um, firmou-se como uma ciência multiparadigmática e, consequentemente, multifacetada. Sob tais condições, essa ciência edificou-se entre as veredas do positivismo e do idealismo, aptos à apreensão do objeto nas suas aparências fenomênicas.

$\mathrm{Na}$ especificidade dos métodos adotados elaborou teorias associacionistas, materialistas-mecanicistas, racionalistas e introspeccionistas, culminando, em síntese, em inúmeros conjuntos de constructos que não encontram equilíbrio no pêndulo da balança - ora primando por uma objetividade sem sujeito, ora primando por um subjetivismo sem objetividade. Para Vigotski, a superação dessa condição identificava-se com a construção de uma teoria do materialismo psicológico ou dialética da psicologia.

Na sequência, nos reportamos ao estofo filosófico da psicologia vigotskiana, ou seja, ao materialismo histórico-dialético, tendo em vista apontar elementos que auxiliem a identificação dos traços característicos fundamentais da psicologia concreta na condição de teoria do materialismo psicológico. Como tal, identificamos que o primeiro traço diz respeito ao enfoque materialista dos fenômenos psicológicos; o segundo, à consideração de que na base de todas as relações sociais estão as relações sociais de produção; o terceiro, concernente à luta contra as condições que alienam o trabalho e o trabaIhador e, por último, a adoção do materialismo dialético por essa psicologia.

Em face do exposto consideramos pertinente, a título de exemplificação, demarcar os referidos traços em produções de Vigotski e, para tanto, principiamos colocando em tela o seu posicionamento metodológico materialista - traço fundante de seu arcabouço teórico como psicologia concreta. Fazemos isso colocando em tela, de partida, a necessidade de elaboração de uma psicologia geral que conferisse unidade a todas as suas ramificações ou especializações e, na sequência, no que tange à apreensão lógica e histórica do psiquismo humano, o que significa dizer, o enfoque ontológico e gnosiológico pelo qual deu seus contributos à psicologia. Por último, 


\section{M." INTERACÃO EM PSICOLOGIA}

apelamos ao conceito de vivência, como unidade mínima de análise da relação indivíduo-sociedade.

Em relação ao primeiro ponto, ele considerou que os sistemas psicológicos tradicionais se encontravam aprisionados a três objetos: o psíquico e suas propriedades; o comportamento e o inconsciente. Tratavam-se, segundo ele, de três fatos psicológicos diferentes, cujas explicações trilhariam caminhos tanto mais distintos entre si quanto mais aprofundados seus percursos particulares. Diferentemente do que se possa imaginar, o que Vigotsky (1997) colocava em causa não era a necessidade de primeiro haver uma psicologia geral e depois suas especializações. Pelo contrário, segundo ele, a psicologia geral deveria ser resultante das teorias, das leis e dos métodos que colocassem a descoberto os traços dos fatos tomados da realidade para estudo, encontrando neles o dado comum. Por essa via, ao invés de seguirem como ciências independentes e distintas, confluiriam na descoberta do elemento comum que reuniria, então, as diversas ramificações científicas em torno de um núcleo compartilhado.

Essa proposição nos interessa por seu conteúdo, mas adquire importância, também, por evidenciar a adoção que Vigotski fazia do método materialista dialético. Para ele, no ponto de partida, teríamos os fatos psicológicos captáveis da realidade, porém, em suas manifestações imediatas, parciais e sincréticas. Tomá-los para análise deveria ser a primeira tarefa e, pelo movimento lógico indutivo, decodificando suas particularidades, chegar-se-ia às suas expressões mais gerais, formulados em conceitos, leis, etc. Das identificações de tais expressões - no contraponto entre diferentes objetos e diferentes explicações, a tarefa seria a identificação do traço comum, portanto, universal, a ser agora, pela via dedutiva, contraposto com novos graus de generalização às expressões particulares do ponto de partida.

Portanto, a psicologia científica superaria o percurso indutivo próprio à psicologia tradicional sem abrir mão dele. Incorporando-o por superação ao movimento lógico dedutivo chegaria ao seu conceito de "mercadoria", ou, unidade mínima de análise - tal como Marx chegara na análise da sociedade burguesa. Contudo, opondo-se a muitos psicólogos soviéticos, ele era contra uma transposição linear e mecânica dos preceitos do materialismo histórico-dialético para a psicologia. Vigotski entendia que tais preceitos deveriam operar como critérios ou como parâmetros metodológicos na explicação do objeto da psicologia, chegando assim ao que ele chamou de teoria do materialismo psicológico. Disso resulta a proposição de que a psicologia deveria elaborar o seu próprio "O Capital".

Nessa direção, urgia a necessidade da apreensão lógica e histórica acerca do psiquismo humano. 0 primeiro desdobramento dessa premissa é a afırmação de que o objeto da psicologia deveria ser o processo de formação, o desenvolvimento, dos fenômenos psicológicos - e não o produto, tal como o faziam as psicologias objetivistas ou subjetivistas. Decodificar o processo seria, porém, sinônimo de explicá-lo, o que é diferente de meramente descrevê-lo. E, nesse trabaIho explicativo, arqueológico, desmistificar a natureza dos processos fossilizados, isto é, aparentemente naturais, mas socialmente formados e que se ocultam na base do funcionamento psíquico (Vigotsky, 1995).

Eis, para ele, o caminho que conduziria à constatação da natureza social do desenvolvimento humano, o que significa dizer: entendê-lo como expressão das contradições históricas entre natureza e cultura. A formação humana assim compreendida se revela um processo ativo e mediado. Um processo que pressupõe, necessariamente, sujeito, objeto e interposição de signos entre eles. Ao afirmar o método dialético para o estudo do homem concreto, Vigotsky (1995) descortinou a possibilidade científica de explicação do psiquismo como, ao mesmo tempo, estrutura orgânica e imagem subjetiva da realidade, superando as cisões entre fenômenos psíquicos e mundo material. Conforme Martins (2013), precisamente nisso reside a materialidade do psiquismo humano, ou seja, sua base material orgânica e a materialidade do objeto representado na imagem psíquica sob a forma de ideia. A nosso juízo, essa proposição elucida o enfoque materialista tal como anunciado na condição de primeira característica de uma psicologia concreta.

0 autor supracitado postulou, ainda, que às características biológicas asseguradas pela evolução das espécies são acrescidas outras, produzidas na história de cada indivíduo singular por decorrência da internalização de signos, as quais denominou funções psíquicas superiores. Nessa direção, afırmou que o desenvolvimento do psiquismo humano e as funções que o instituem não decorrem de uma evolução natural, outrossim, de sua própria natureza social consubstanciada no trabalho.

Ao introduzir o conceito de signo, Vigotsky (1997) alertou sobre a necessidade de se distinguir, no desenvolvimento psíquico, os modos de funcionamento naturais e as formas culturalmente instituídas. Os primeiros decorrentes do processo de evolução e comuns aos homens e demais animais superiores, os segundos, produtos da evolução histórica e especificamente humanos. A peculiaridade da formação do psiquismo humano decorre, pois, da transformação da relação entre homem e natureza quando, graças ao desenvolvimento da linguagem - sistema de signos, ele superou a fusão entre estímulo e resposta própria ao comportamento dos animais. Assim, o signo passa a operar como estímulo de segunda ordem que, retroagindo sobre as funções psíquicas, transforma suas manifestações espontâneas em expressões volitivas.

Esse autor afirmou, então, que da mesma maneira que o instrumento técnico de trabalho modifica a adaptação natural determinando as formas de operações de trabalho, isto é, o domínio da natureza, o uso de signos modifica radicalmente o desenvolvimento e a estrutura das funções psíquicas, possibi- 


\section{MLE INTERACÃO EM 2. PSICOLOGIA}

litando o autodomínio do comportamento. Se pelo trabalho o homem colocou a natureza sob seu domínio, pelo emprego de signos ele dominou a si mesmo, condição requerida pela própria atividade de trabalho. Os instrumentos técnicos de trabaIho e o uso de signos inauguram, portanto, outra forma de relação homem-natureza, isto é, inauguram relações mediadas.

Segundo Martins (2013), para Vigotski a internalização de signos é nuclear na defesa da tese acerca da natureza social do psiquismo humano, posto que esse processo interpenetra a sociedade que produz e comporta os signos, o ser social que os porta por interiorização e a decorrente transformação que ela provoca nos processos psíquicos, a serem manifestas na própria produção da vida social por meio do trabalho. Consideramos que essa proposição exemplifica a segunda característica de uma psicologia concreta, qual seja, na base de todas as relações sociais estão as relações sociais de produção.

Pelo exposto consideramos inconteste a afirmação vigotskiana acerca da natureza social do desenvolvimento psíquico, dado que pode suscitar uma interrogação: como, um ser que é social por natureza se torna um ser singular, único e irrepetível? A nosso juízo Vigotsky (1996) fornece esta resposta na proposição do conceito de vivência (perejivanie) que representa, em última instância, a unidade de pessoa e sua situação social de desenvolvimento. Compreender perejivanie como unidade é mais do que apreender de modo interacionista a relação sujeito - objeto, implica reconhecer que ela não resulta nem do polo sujeito nem do polo objeto' - entendido como entorno físico e social da pessoa, mas do entrelaçamento que particularmente se trava entre ambos ao longa da história do indivíduo.

Entender a natureza social do desenvolvimento demanda reconhecer que o ambiente, a realidade objetiva não é um ente em si mesmo, mas sim, objeto da vivência singular de inúmeras mediações particulares presentes na atividade realizada pela pessoa, atividade que é, por sua vez, condicionada pela prática histórico-socialmente formada pelo conjunto dos homens, ou seja, pela dimensão universal da vida coletiva. Por essa via, o objetivo se converte em subjetivo, o material em ideal, o social em individual. Portanto, concluímos que para Vigotski o entorno físico e social não influi de modo imediato sobre o desenvolvimento - tal como para os demais animais superiores, mas sim, pela mediação da vivência que o sujeito tenha dele, vivência essa sustentada objetivamente pela realidade concreta e orientada pelos significados e sentidos experienciados pelo sujeito.

Haja vista que a vivência se sustenta pela realidade concreta, há que se levar em conta, nela, os reflexos pessoais das determinações econômicas e políticas da estrutura social, tal como proposto por Vigotski, sem perdermos de vista que vivemos numa sociedade capitalista, produtora de mercado- rias, universalizadora do valor de troca, enfim, numa sociedade essencialmente alienada e alienante, cujo enfrentamento exige clareza subjetiva e vínculos coletivos objetivos de luta. Tal fato se justifica uma vez que em relações sociais de dominação, quando os processos de apropriação e objetivação são alienados e alienantes, a vivência se empobrece, limitando os próprios alcances do desenvolvimento psíquico. Por isso, como psicologia concreta, as proposições vigotskianas nos conclamam à luta contra as condições objetivas e subjetivas que alienam o trabalho e o trabalhador.

\section{CONTRIBUIÇÃO DE CADA AUTOR}

Certificamos que todos os autores participaram suficientemente do trabalho para tornar pública sua responsabilidade pelo conteúdo.

\section{DECLARAÇÃO DE CONFLITOS DE INTERESSE}

Os autores declaram que não há conflitos de interesse no manuscrito submetido.

\section{REFERÊNCIAS}

Duarte, N. (1993) A individualidade para si: contribuição a uma teoria histórico-social da formação do indivíduo. Autores Associados.

Kopnin, P. V. (1978) A dialética como lógica e teoria do conhecimento. Civilização Brasileira.

Kosik, K. (1976). Dialética do concreto. Paz e Terra.

Martins, L. M. (2013) O desenvolvimento do Psiquismo e a Educação Escolar: contribuições à luz da psicologia histórico-cultural e da pedagogia histórico-crítica. Autores associados.

Marx, K. \& Engels, F. (1993). A Ideologia Alemã (Feuerbach). Hucitec.

Marx, K. (1986). Elementos fundamentales para la crítica de la economia política. Siglo Veinteuno.

Marx, K. (2004). Manuscritos econômico-filosóficos. Boitempo. Vigotsky, L. S. (1997). Obras Escogidas. Tomo I. Visor.

Vigotsky, L. S. (1995). Obras Escogidas. Tomo III. Visor.

Vigotsky, L. S. (1996). Obras Escogidas. Tomo IV. Visor.

Submetido em: 11/04/20 $1^{\text {a }}$ decisão editorial: $25 / 05 / 20$ Aprovação: 02/06/20 